\title{
Effect of Solid Particles on the Gas Hold Up in the Fluidized Bed Columns: Experimental and Mathematical Studies
}

\author{
Adiba A. Mahmmod ${ }^{1}$, Anees A. Khadom 1,* (D) \\ 1 Department of Chemical Engineering - College of Engineering - University of Diyala - Baquba City 32001, Daiyla \\ governorate, Iraq; aneesdr@gmail.com (A.A.K.); \\ * Correspondence: aneesdr@gmail.com (A.A.K.);
}

Scopus Author ID 26654896500

Received: 31.07.2021; Revised: 15.09.2021; Accepted: 19.09.2021; Published: 17.10.2021

\begin{abstract}
The present research investigated the effect of solid properties on the gas holdup of the fluidization bed bubble columns (FBCS). All experiments were performed in the constant clear tap water of $80 \mathrm{~cm}$ height. The range of solid particle diameters was $0.7-2 \mathrm{~mm}$ with two different densities of 1075 and $1200 \mathrm{~kg} / \mathrm{m}^{3}$, superficial air velocities $4-7 \mathrm{~cm} / \mathrm{s}$. It was observed that there are proportional relationships between superficial gas velocity and particle diameter with the gas holdup. While an inverse relationship between solid concentration and particle density with the gas holdup. Mathematical and statistical analysis was also used as a powerful way to represent the gas hold up as a function of different operating conditions.
\end{abstract}

Keywords: solid properties; loading; gas hold up; superficial gas velocity; regression.

(C) 2021 by the authors. This article is an open-access article distributed under the terms and conditions of the Creative Commons Attribution (CC BY) license (https://creativecommons.org/licenses/by/4.0/).

\section{Introduction}

Fluidization innovation is presently connected worldwide for many generally differing applications, going from substance changes to polymer combination, adsorption, drying, and numerous other forms [1]. One fluidized bed pattern is a gas-liquid-solid fluidized system, which is a batch of solid particles that fluidized by a co-current up the flow of liquid as the continuous phase and gas as the dispersed bubble phase. This system has developed as one of the most promising technology in chemical and petrochemical applications in the latest years. While late accentuation has been given on the ideal plan and the operation of the gas-liquidsolid fluidized bed, it is similarly critical to look at the attributes of the three-stage operation with liquid as the continuous stage. Accordingly, the hydrodynamic properties, for example, the bed pressure drop, minimum fluidization velocity, bed porosity, phase holdups, bubble properties, and the mixing characteristics have to be studied keeping in mind the end goal to give the essential data required to the plan of such fluidized-bed frameworks [1]. Bubble column reactors (BCRs) fit the common multiphase reactors, which are made of three main kinds: the trickle bed reactor (fixed or packed bed), fluidized bed reactor, and the bubble column reactor. BCRs are essentially cylindrical vessels with a gas distributor at the lowest base. The gas is sparged in the form of bubbles into either a liquid phase or a liquid-solid suspension. BCRs are usually mentioned as slurry bubble column reactors when a solid phase exists. Bubble columns are intensively used as multiphase contactors and reactors in chemical, petrochemical, biochemical, and metallurgical industries [2,3]. The solids could also be inert 
and only present to increase mass transfer between phases, as is often the case, e.g., in a trickle flow reactor. Three-phase fluidized describes a gas-liquid-solid $(G L S)$ flow system in which particles are in motion induced by gas and or liquid phases [4]. In $G L S$ fluidized bed, the solid particles are fluidized by an upward co-current flow of the two-fluid phase. One of the fluids can be a liquid and aids as the continuous phase, while the other gas serves as the dispersed phase [5]. The gas holdup is a dimensionless key parameter for the phenomena purposes of bubble column systems [6]. The process of causing solids to behave like fluids by forcing gas or liquid upwards through a solid-filled reactor is known as fluidization [7]. The gas holdup in the $G L S$ fluidized bed varies strongly with bubble flow properties, depending on the particles' gas flow rate, liquid flow rate, and physical properties. Bubble flow in a $G L S$ fluidized bed can be classified into three distinct regimes: dispersed bubble flow regime coalesced bubble flow regime and slug flow regime [8]. Gas holdup can be defined as the ratio of the volume of gas to the total volume of gas and liquid mixture in a finite column length. In order to predict gas holdup values, it is necessary to know the relationship between gas-liquid slip velocity and gas holdup. All studies examine gas holdup because it plays an important role in designing and analyzing bubble columns. The presence of solids led to a larger bubble size [9]. This was attributed to an increase in the apparent slurry concentration; for particles less than $1 \mathrm{~mm}$ in size, the gas holdup was significantly reduced by the presence of elements or particles. This was because small particles enhance coalescence, resulting in higher increasing velocities, whereas larger particles were found to have a less significant influence. [10]. Since these particles instead tend to cause the breakup of the bubbles [11]. Many academics and researchers have tried to forecast the size of the bubbles, including not just variations in mean size but also distributions of volumes and diameters [12].

\section{Materials and Methods}

Experiments were performed in a glass column with $15 \mathrm{~cm}$ inner diameter and $100 \mathrm{~cm}$ height. The experimental study was carried out to investigate the effect of solid (particles) properties, solid loading, and superficial gas velocity on the gas holdup. Air was used as the gas phase that compressed and passed through a stabilizer then was fed to the column. Plastic particles were used as a solid phase with a density of $1075 \mathrm{~kg} / \mathrm{m}^{3}(0.7,1.25$, and $2 \mathrm{~mm}$ diameter $)$ and $1200 \mathrm{~kg} / \mathrm{m}^{3}(0.7,1$, and $2 \mathrm{~mm}$ diameter). Three concentrations of these particles $(0,7,15$ $\%) \mathrm{kg}$ solid $/ \mathrm{kg}$ (water+ solid) were used in the experimental work. In all experiments, the level of clear liquid water was kept at $80 \mathrm{~cm}$ and filled with solid particles at desired conditions. A needle valve was used to adjust the flow rate of the air at the desired range of gas velocity $\left(\mathrm{U}_{\mathrm{g}}\right)$. The schematic representation of the three-phase fluidized bed is shown in Figure 1. Gas hold up $\left(\epsilon_{g}\right)$ was calculated using the following equation:

$$
\epsilon_{g}=\frac{H_{f}^{o}-H_{f}}{H_{f}^{o}}
$$

where $H_{f}^{\rho}$ and $H_{f}$ are the height of liquid level in the column after and before the addition of solid particles, respectively. 


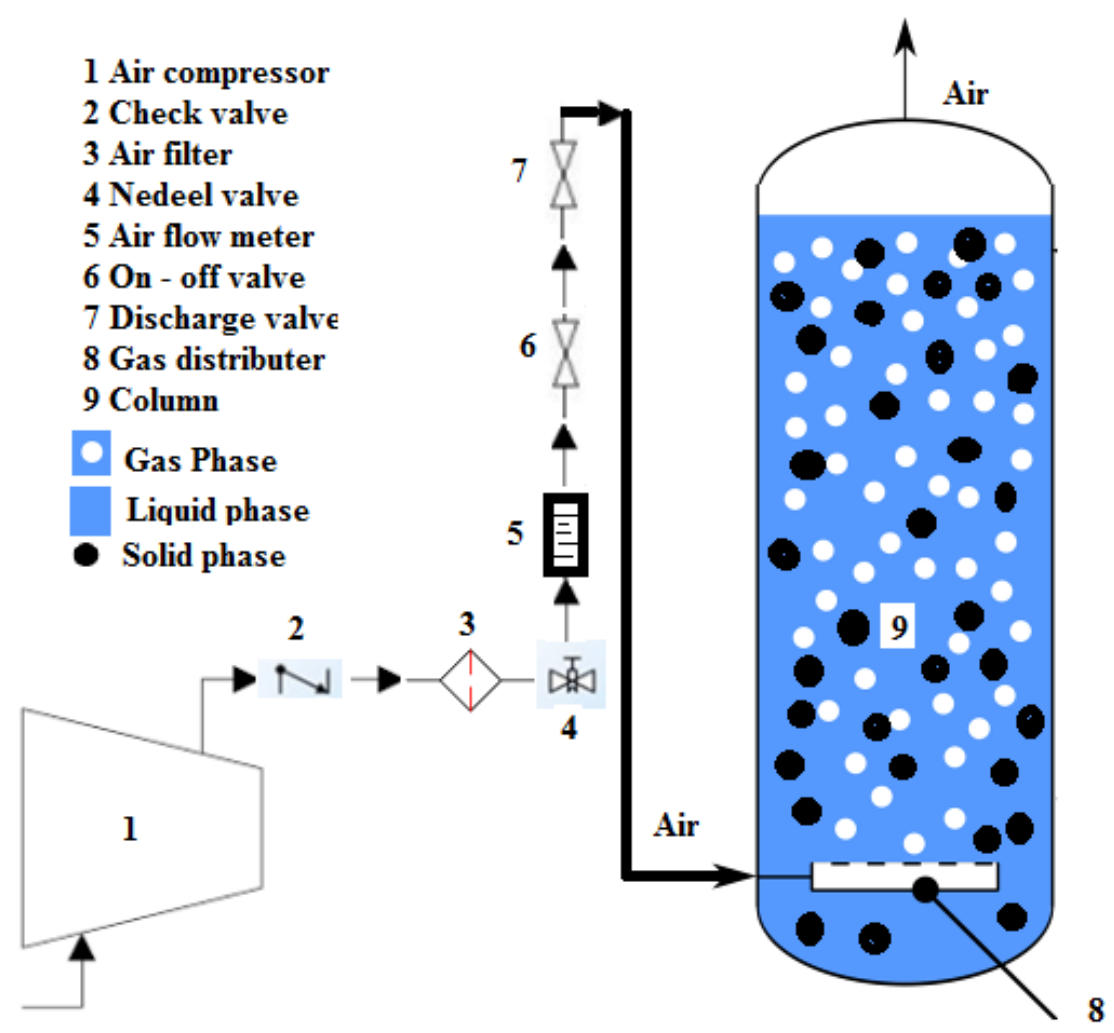

Figure 1. Schematic diagram of the three-phase fluidized bed.

\section{Results and Discussion}

\subsection{Experimental studies: effect of operating conditions.}

Figures 2 and 3 show the effect of superficial gas velocity on the gas holdup, which indicates that gas holdup increases approximately linearly with an increase in the superficial gas velocity. This behavior is in agreement with the findings of Thorat and Joshi [13]. Figures 2 and 3; also show the measured gas holdup for various particle diameters. A proportional relationship between particle diameter and measured gas holdup was seen, which can be attributed to the rate of bubble coalescence increasing as the particle diameter decreases. As a result of bubble coalescence, gas holdup reduces. This tendency is consistent with the observations of Kantarci et al. [14]. Figure 4 shows the relationship between gas holdup and particles density. There is an inverse relationship between particle density and gas holdup. This is acceptable with many literature results $[15,16]$. Figures 5 and 6 show the relationship between gas holdup and particles concentrations. There is an inverse relationship between particle concentrations and gas holdup because of the rate of bubble coalescence.

\subsection{Mathematical studied: modeling and statistical analysis.}

Table 1 shows the effect of particle size, $d_{p}\left(X_{1}, m m\right)$, solid density, $\rho_{\mathrm{s}}\left(X_{2}, \mathrm{~kg} / \mathrm{m}^{3}\right)$, gas velocity, $\mathrm{U}_{\mathrm{g}}\left(\mathrm{X}_{3}, \mathrm{~cm} / \mathrm{s}\right)$, and solid concentration, $\mathrm{C}_{\mathrm{s}}\left(\mathrm{X}_{4}, \%\right)$ on gas holdup, $\varepsilon_{\mathrm{g}}(\mathrm{Y})$. Figures $2-$ 6 show that gas holdup varies in different ways. The variation may be linear, polynomial, or exponential. Therefore, a mathematical model was suggested to represent the gas holdup data. Polynomial Interaction Model (PIM) takes into account all the probabilities of variables (i.e., individual and interaction effects) [17 - 19]. This model was shown in equation 2. 

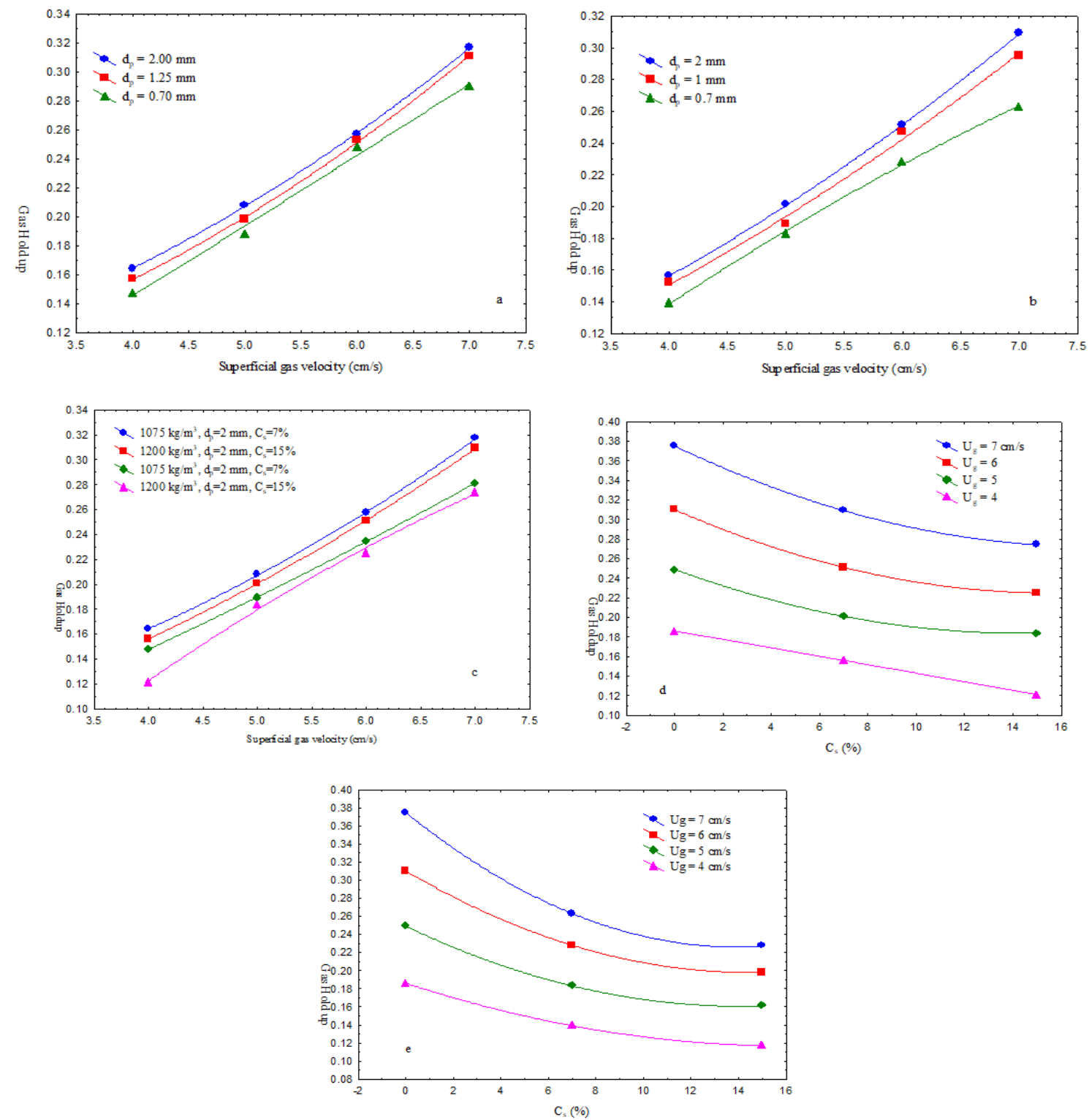

Figure 2 Gas holdup against different operating conditions: (a) superficial gas velocity for different $d_{p}$ and $\rho_{s}=$ $1075 \mathrm{~kg} / \mathrm{m}^{3}$; (b) Gas holdup against superficial gas velocity for different $d_{\mathrm{p}}$ and $\rho_{\mathrm{s}}=1200 \mathrm{~kg} / \mathrm{m}^{3}$; (c) Gas holdup

against superficial gas velocity for different densities at the same diameter; (d) Gas holdup against solid concentration for different $\mathrm{U}_{\mathrm{g}}$ at $\rho s=1200 \mathrm{~kg} / \mathrm{m}^{3}$ and $\mathrm{d}_{\mathrm{p}}=2.0 \mathrm{~mm}$; (e) Gas holdup against solid concentration for different $\mathrm{U}_{\mathrm{g}}$ at $\rho s=1200 \mathrm{~kg} / \mathrm{m}^{3}$ and $\mathrm{d}_{\mathrm{p}}=0.7 \mathrm{~mm}$.

$$
\begin{gathered}
Y=a_{o}+a_{1} X_{1}+a_{2} X_{1}^{2}+a_{3} X_{1} X_{2}+a_{4} X_{1} X_{3}+a_{5} X_{1} X_{4}+a_{6} X_{2}+a_{7} X_{2}^{2}+a_{8} X_{2} X_{3}+ \\
a_{9} X_{2} X_{4}+a_{10} X_{3}+a_{11} X_{3}^{2}+a_{12} X_{3} X_{4}+a_{13} X_{4}+a_{14} X_{4}^{2}
\end{gathered}
$$

where; $a_{0}, a_{1}, a_{2}, \ldots a_{14}$ are constants of the model. STATISTICA 7 software was used to evaluate the coefficients of PIM. This software was based on the Levenberg-Marquardt nonlinear estimation least-squares method, confidence level $95 \%$, a maximum number of iteration 1000 , convergence criterion $1 \times 10^{-6}$. The second-order polynomial model takes into account the individual effect of each variable and the interaction between them. The numerical values of these coefficients are shown in equation 3.

$Y=46616.2-1347.4 X_{1}+499 X_{1}^{2}+3 \times 10^{-5} X_{1} X_{2}+3 \times 10^{-3} X_{1} X_{3}+1 \times$ $10^{-3} X_{1} X_{4}-81 X_{2}-4 \times 10^{-2} X_{2}^{2}-1 \times 10^{-5} X_{2} X_{3}-7 \times 10^{-6} X_{2} X_{4}+7 \times 10^{-2} X_{3}+$ $2.3 \times 10^{-4} X_{3}^{2}-1.2 \times 10^{-3} X_{3} X_{4}+3.5 \times 10^{-3} X_{4}+3.3 \times 10^{-4} X_{4}^{2}$ 
Equation 3 represents the gas holdup data with high correlation coefficients $\mathrm{R}^{2}(0.9959)$. As shown in Figure 7, the best fitting was obtained via PIM. In general, a correlation coefficient up to 0.30 indicates a poor relationship; between 0.50 and 0.70 indicates a significant relationship and is of practical importance; while above 0.90 means a strong relationship [20, $21]$. Table 2 collects the results of the analysis of variance (ANOVA). Probability ( $p$-value) is the smallest level of significance that would lead to the rejection of the null hypothesis. The probability for ANOVA is smaller than 5\% confirmed the validity of the suggested model. Furthermore, $F$-values from $F$ distribution tables ( $\mathrm{F}$ - table) were also shown in Table 2 . These values were lower than the $F$-values calculated, which means that at $95 \%$ confidence levels, the regression coefficients are statically greater than zero, and they should be kept in the models. The predicted gas holdup values by IPM against the experimental one are shown in Figure 7. The intercept of the fitting line is closed to zero (0.001), and the slope approach unity (0.99) indicates high accuracy of IPM.

Table 1. Experimental operating conditions and gas holdup.

\begin{tabular}{|c|c|c|c|c|c|}
\hline Run & $\begin{array}{c}\mathbf{d}_{\mathrm{p}}(\mathbf{m m}) \\
\mathbf{X}_{1}\end{array}$ & $\begin{array}{c}\rho_{\mathrm{s}}\left(\mathrm{kg} / \mathrm{m}^{3}\right) \\
X_{2}\end{array}$ & $\begin{array}{c}\mathbf{U}_{\mathrm{g}}(\mathbf{c m} / \mathbf{s}) \\
\mathbf{X}_{3}\end{array}$ & $\begin{array}{c}\mathrm{Cs}(\%) \\
\mathrm{X}_{4}\end{array}$ & $\begin{array}{l}\varepsilon_{\mathbf{g}} \\
\mathbf{Y}\end{array}$ \\
\hline 1 & 2 & 1200 & 4 & 0 & 0.1862 \\
\hline 2 & 2 & 1075 & 4 & 0 & 0.1862 \\
\hline 3 & 2 & 1200 & 4 & 7 & 0.156 \\
\hline 4 & 2 & 1075 & 4 & 7 & 0.164 \\
\hline 5 & 2 & 1200 & 4 & 15 & 0.121 \\
\hline 6 & 2 & 1075 & 4 & 15 & 0.148 \\
\hline 7 & 2 & 1200 & 5 & 0 & 0.249 \\
\hline 8 & 2 & 1075 & 5 & 0 & 0.249 \\
\hline 9 & 2 & 1200 & 5 & 7 & 0.201 \\
\hline 10 & 2 & 1075 & 5 & 7 & 0.208 \\
\hline 11 & 2 & 1200 & 5 & 15 & 0.184 \\
\hline 12 & 2 & 1075 & 5 & 15 & 0.189 \\
\hline 13 & 2 & 1200 & 6 & 0 & 0.31 \\
\hline 14 & 2 & 1075 & 6 & 0 & 0.31 \\
\hline 15 & 2 & 1200 & 6 & 7 & 0.251 \\
\hline 16 & 2 & 1075 & 6 & 7 & 0.257 \\
\hline 17 & 2 & 1200 & 6 & 15 & 0.225 \\
\hline 18 & 2 & 1075 & 6 & 15 & 0.235 \\
\hline 19 & 2 & 1200 & 7 & 0 & 0.375 \\
\hline 20 & 2 & 1075 & 7 & 0 & 0.375 \\
\hline 21 & 2 & 1200 & 7 & 7 & 0.309 \\
\hline 22 & 2 & 1075 & 7 & 7 & 0.317 \\
\hline 23 & 2 & 1200 & 7 & 15 & 0.274 \\
\hline 24 & 2 & 1075 & 7 & 15 & 0.281 \\
\hline 25 & 0.7 & 1200 & 4 & 0 & 0.186 \\
\hline 26 & 0.7 & 1075 & 4 & 0 & 0.186 \\
\hline 27 & 0.7 & 1200 & 4 & 7 & 0.139 \\
\hline 28 & 0.7 & 1075 & 4 & 7 & 0.147 \\
\hline 29 & 0.7 & 1200 & 4 & 15 & 0.117 \\
\hline 30 & 0.7 & 1075 & 4 & 15 & 0.129 \\
\hline 31 & 0.7 & 1200 & 5 & 0 & 0.249 \\
\hline 32 & 0.7 & 1075 & 5 & 0 & 0.249 \\
\hline 33 & 0.7 & 1200 & 5 & 7 & 0.183 \\
\hline 34 & 0.7 & 1075 & 5 & 7 & 0.188 \\
\hline 35 & 0.7 & 1200 & 5 & 15 & 0.161 \\
\hline 36 & 0.7 & 1075 & 5 & 15 & 0.165 \\
\hline 37 & 0.7 & 1200 & 6 & 0 & 0.31 \\
\hline 38 & 0.7 & 1075 & 6 & 0 & 0.31 \\
\hline
\end{tabular}




\begin{tabular}{c|c|c|c|c|c}
\hline \multirow{2}{*}{$\mathbf{R u n}$} & $\mathbf{d}_{\mathbf{p}}(\mathbf{m m})$ & $\mathbf{\rho}_{\mathbf{s}}\left(\mathbf{k g} / \mathbf{m}^{\mathbf{3}}\right)$ & $\mathbf{U}_{\mathbf{g}}(\mathbf{c m} / \mathbf{s})$ & $\mathbf{C s}(\mathbf{\%})$ & $\mathbf{X}_{\mathbf{g}}$ \\
& $\mathbf{X}_{\mathbf{1}}$ & $\mathbf{X}_{\mathbf{2}}$ & $\mathbf{X}_{\mathbf{3}}$ & $\mathbf{Y}$ \\
\hline 39 & 0.7 & 1200 & 6 & 7 & 0.228 \\
\hline 40 & 0.7 & 1075 & 6 & 15 & 0.254 \\
\hline 41 & 0.7 & 1200 & 6 & 15 & 0.198 \\
\hline 42 & 0.7 & 1075 & 6 & 0 & 0.216 \\
\hline 43 & 0.7 & 1200 & 7 & 0 & 0.375 \\
\hline 44 & 0.7 & 1075 & 7 & 7 & 0.263 \\
\hline 45 & 0.7 & 1200 & 7 & 7 & 0.29 \\
\hline 46 & 0.7 & 1075 & 7 & 15 & 0.227 \\
\hline 48 & 0.7 & 1200 & 7 & 15 & 0.264
\end{tabular}

Table 2. Analysis of variance.

\begin{tabular}{c|c|c|c|c|c|c} 
& Sum of squares & Freedom degree & Mean squares & F test & F table & P value \\
\hline Regression & 2.8300 & 15 & 0.188505 & 3314 & 2.23 & $1 \times 10^{-7}$ \\
\hline Residual & 0.0018 & 33 & 0.000057 & & & \\
\hline Total & 2.8318 & 48 & & & &
\end{tabular}

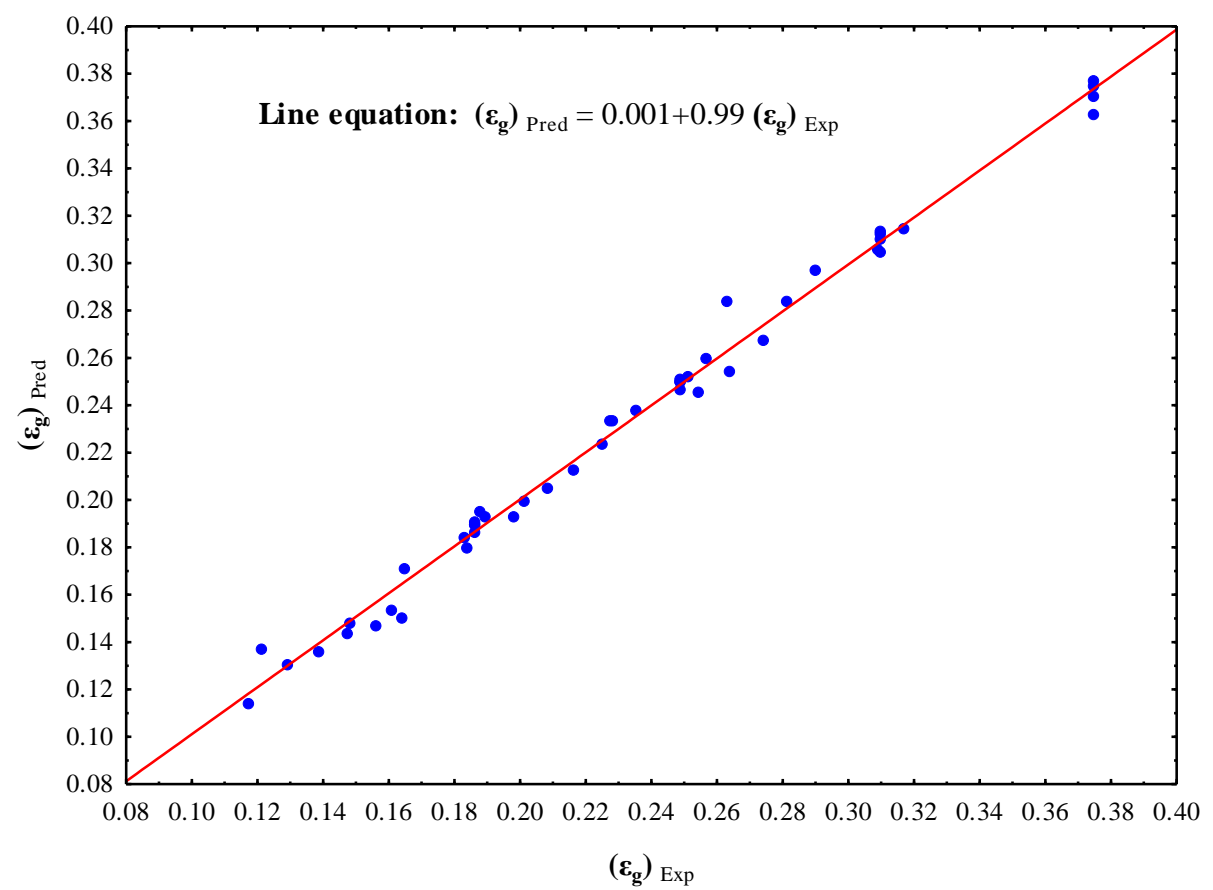

Figure 7. Predicted gas holdup against experimental gas holdup obtained by PIM.

\section{Conclusions}

Experiments have been achieved for three-phase bubble columns in a batch solid and liquid phase and co-current mode of gas-phase operation. The gas holdup is decreasing with an increase in solid concentration. The gas holdup is proportional to superficial gas velocity. It increases greatly with increasing the gas velocity. There is a proportional relationship between gas holdup and particle diameter for the specified operating conditions, increasing particle density decreasing gas holdup.

\section{Funding}

This research received no external funding. 


\section{Acknowledgments}

The authors would like to thank the Department of Chemical Engineering, College of Engineering, University of Diyala.

\section{Conflicts of Interest}

The authors declare that they have no known competing financial interests or personal relationships that could have appeared to influence the work reported in this paper.

\section{References}

1. Islam, M. T.; Nguyen, A. V. Bed expansion and gas holdup characteristics of bubble-assisted fluidization of liquid-particle suspensions in a HydroFloat cell, Minerals Engineering 2021, 160, 1, 106678, https://doi.org/10.1016/j.mineng.2020.106678.

2. Hoe-Jong, K.; Jin-Hyun, K. Cavitation bubble- and gas bubble-induced fractional precipitation of paclitaxel from Taxus chinensis, Process Biochem. 2020, 99 316-323, https://doi.org/10.1016/j.procbio.2020.09.020.

3. Raymond, L., Rujuan Mo Wei Shan Beverly Sim, Bubble characteristics in shallow bubble column reactors, Chem Eng Res Des. 2010, 88, 197-203, https://doi.org/10.1016/j.cherd.2009.07.008.

4. Chen, J.; Brooks S. C. Experiments and CFD simulation of mass transfer and hydrodynamics in a cylindrical bubble column, Chem. Eng. Sci. 2021, 234, 116435, https://doi.org/10.1016/j.ces.2020.116435.

5. Mojtaba, M.; Jamal, C. Effect of solid loading and particle size on the phase holdup distribution and bubble behaviour in a pilot-scale slurry bubble column, Chem. Eng. Sci. 2021, 243, 116732, https://doi.org/10.1016/j.ces.2021.116732.

6. Keon, B.; Gang S. G.; Nam S. N.; Young I.; Jong W. B.; Dong H. L. Bubble characteristics in pressurized bubble column associated with micro-bubble dispersion, Chem Eng. J. 2020, 386, 121339, https://doi.org/10.1016/j.cej.2019.03.215.

7. Stachnik, M.; Jakubowski, M. Multiphase model of flow and separation phases in a whirlpool: Advanced simulation and phenomena visualization approach, Journal of Food Engineering 2020, 274, 109846, https://doi.org/10.1016/j.jfoodeng.2019.109846.

8. Ali. H J. Hydrodynamics Characteristics of Three Phase non-Newtonian Liquid-Gas and Solid Fluidized Beds, Ph .D. Thesis, University of Tech. Chem. Eng. Dept. 2006.

9. GuoLi, W.; Liu, W. C. Thermal diffusion response to gas-liquid slug flow and its application in measurement, Int. J. Heat Mass Transf. 2020, 159, 120065, https://doi.org/10.1016/j.ijheatmasstransfer.2020.120065.

10. Li, H. and Prakash, A. Heat transfer and hydrodynamics in a three-phase slurry bubble column, Ind. Eng. Chem. Res. 1997, 36, 4688-4694, https://doi.org/10.1021/ie9701635.

11. Enzu, Z.; Murray R.; Shibo, K.; Andrew C. Turbulent coarse-particle non-Newtonian suspension flow in a pipe, Int. J. Multiph. Flow. 2021, 142, 103698, https://doi.org/10.1016/j.ijmultiphaseflow.2021.103698.

12. Gakingo, G.K.; Clarke, K.G.; Louw, T.M. A numerical investigation of the hydrodynamics and mass transfer in a three-phase gas-liquid-liquid stirred tank reactor, Biochem. Eng. J. 2020, 175, 107522, https://doi.org/10.1016/j.bej.2020.107522.

13. Thorat, B.N.; Joshi, J.B. Regime Transition in Bubble Columns: Experimental and Predictions. Exp. Therm. Fluid Sci. 2004, 28, 423 - 430, https://doi.org/10.1016/j.expthermflusci.2003.06.002.

14. Kantarcia, N.; Borakb, F.; Ulgena, K. O. Bubble column Reactors, Process Biochem. 2005, 40, 2263 - 2283, https://doi.org/10.1016/j.procbio.2004.10.004.

15. Liu, T. J. Bankoff, S.G. Structure of air-water bubbly flow in a vertical pipe-II. Void fraction, bubble velocity and bubble size distribution, Int. J. Heat Mass Transf. 1993, 36, 1061-1072, https://doi.org/10.1016/S0017-9310(05)80290-X.

16. Mühlbauer, A.; Hlawitschka, M.W.; Bart, HJ. Modeling of solid-particle effects on bubble breakage and coalescence in slurry bubble columns. Exp. Comput. Multiph. Flow 2021, 3, 303-317, https://doi.org/10.1007/s42757-020-0078-y.

17. Khadom, A.A.; Mahdi, M.S.; Mahood, H.B. Mathematical Regression and Artificial Neural Network for Prediction of Corrosion Inhibition Process of Steel in Acidic Media. J Bio Tribo Corros 2020, 6, 92, https://doi.org/10.1007/s40735-020-00390-7. 
18. Mahmmod, A.A.; Khadom, A.A.; Mahood, H.B. Experimental Modeling of Inhibition's Mechanism of Cupronickel Alloy by DETA and EDA into Acid Corrosive Media. J Bio Tribo Corros 2020, 6, 85, https://doi.org/10.1007/s40735-020-00381-8.

19. Rashid, K.H.; Khadom, A.A.; Mahood, H.B. Aluminum ASA 6061 Anodizing Process by Chromic Acid Using Box-Wilson Central Composite Design: Optimization and Corrosion Tendency. Met. Mater. Int. 2020, https://doi.org/10.1007/s12540-020-00762-1.

20. Rashid, K.H.; Khadom, A.A. Mathematical Modeling and Electrochemical Behavior for Corrosion Inhibition of Steel by Kiwi Juice Extract. J Bio Tribo Corros 2020, 6, 13, https://doi.org/10.1007/s40735-019-0312-y.

21. Rashid, K.H.; Khadom, A.A. Sodium sulfite as an oxygen scavenger for the corrosion control of mild steel in petroleum refinery wastewater: optimization, mathematical modeling, surface morphology and reaction kinetics studies. Reac Kinet Mech Cat 2020, 129, 1027-1046, https://doi.org/10.1007/s11144-020-01738-3. 